\title{
Synthesis and electro-catalytic activity of methanol oxidation on nitrogen containing carbon nanotubes supported Pt electrodes
}

\author{
T. Maiyalagan * \\ Department of Chemistry, School of Science and Humanities, VIT University, Vellore 632014, India \\ Received 19 June 2007; received in revised form 6 November 2007; accepted 24 November 2007 \\ Available online 5 December 2007
}

\begin{abstract}
Template synthesis of various nitrogen containing carbon nanotubes using different nitrogen containing polymers and the variation of nitrogen content in carbon nanotube (CNT) on the behaviour of supported Pt electrodes in the anodic oxidation of methanol in direct methanol fuel cells was investigated. Characterizations of the as-prepared catalysts are investigated by electron microscopy and electrochemical analysis. The catalyst with $\mathrm{N}$-containing CNT as a support exhibits a higher catalytic activity than that carbon supported platinum electrode and CNT supported electrodes. The N-containing CNT supported electrodes with $10.5 \%$ nitrogen content show a higher catalytic activity compared to other N-CNT supported electrodes. This could be due to the existence of additional active sites on the surface of the N-containing CNT supported electrodes, which favours better dispersion of $\mathrm{Pt}$ particles. Also, the strong metal-support interaction plays a major role in enhancing the catalytic activity for methanol oxidation.
\end{abstract}

(C) 2007 Elsevier B.V. All rights reserved.

Keywords: Template synthesis; Methanol oxidation; Nitrogen containing carbon nanotubes

\section{Introduction}

Carbon materials possess suitable properties for designing of electrodes in electrochemical devices. Therefore, carbon is an ideal material for supporting nano-sized metallic particles in the electrodes for fuel cell applications. Carbon has the essential properties of electronic conductivity, corrosion resistance, surface properties and low cost as required for the commercialization of fuel cells. The conventional support namely carbon black is used for the dispersion of Pt particles [1-3]. New novel carbon support materials such as graphite nanofibers (GNFs) [4,5], carbon nanotubes (CNTs) [6-9], carbon nanohorns [10] and carbon nanocoils [11], provide alternate candidates of carbon support for fuel cell applications. Bessel et al. [4] and Steigerwalt et al. [5] used GNFs as supports for Pt and Pt-Ru alloy electro-catalysts. They observed better activity for methanol oxidation. The high electronic conductivity of GNF and the specific crystallographic orientation of the metal particles resulting from well-ordered GNF support

\footnotetext{
* Tel.: +91 416 2202338; fax: +91 4162243092 .

E-mail address: maiyalagan@gmail.com.
}

are believed to be the factors for the observed enhanced electrocatalytic activity. In heterogeneous catalysis, one of the important tasks is the determination of the number of active sites in the catalyst. For a given catalyst, the number of active sites present is responsible for the observed catalytic activity. Considerable amount of research has been devoted towards understanding the number of active sites as well as the role played by the carrier of the supported catalysts. The most efficient utilization of any supported catalyst depends on the percentage of exposed or the dispersion of the active component on the surface of the carrier material. Among the various factors that influence the dispersion of active component, the nature of the support and the extent of the active component loading are of considerable importance.

Carbon nanotubes, because of their interesting properties such as nanometer size, electronic properties and high surface area, have been receiving increased attention in recent years for their application in fuel cells as supports for catalyst [9]. Modification of the CNTs alters the catalytic activity of the supported catalyst. Doping the carbon with heteroatom could be particularly an interesting way for tuning the surface and electronic properties. Incorporation of nitrogen in the CNT results in the enhancement of conductivity, due to the 
contribution of additional electron by the nitrogen atom $[12,13]$. Doping with high concentrations of nitrogen leads to an increase in the conductivity due to the raise in Fermi level towards the conduction band [14,15]. The profitable effect of nitrogen functionalities on the performance of porous carbon used as an electrode material in the electric double layer capacitors has been reported [16,17]. The presence of nitrogen atom in the carbon support also generates specific surface properties including enhanced polarity, basicity and heterogeneity in terms of hydrophilic sites. This modification is of great interest when considering the application to catalysis and electrochemistry.

Carbon with nitrogen, sulphur and phosphorus functionalities promotes the formation of $\mathrm{Pt}$ particulates relative to unfunctionalised carbon. Electro-catalysts prepared with nitrogenfunctionalised carbon showed the highest activity towards methanol oxidation [18]. While sulphur-functionalised electrode showed the lowest activity towards methanol oxidation, suggesting the existence of specific interaction between $\mathrm{Pt}$ and sulphur on the carbon support which inhibited the rate of the reaction $[19,20]$. Nitrogen functionalisation was accompanied by an increase in basicity of the carbon support, while sulphur functionalisation resulted in an increase of acidity. Nitrogen sites on carbon surfaces were generated using pyrolyzed porphyrins and heterocycles on carbon supports for fuel cell applications $[21,22]$. The presence of nitrogen functional groups in the carbon framework show substantial effect on the catalytic activity in direct methanol fuel cells [23,24].

$\mathrm{N}$-doped CNF electrodes exhibit enhanced catalytic activity for oxygen reduction over non-doped CNF. However, higher dispersion and the electro-catalytic activity of methanol oxidation of $\mathrm{Pt}$ particles on nitrogen containing carbon nanotube support have been reported [25,26]. For the application of carbon nanotubes in catalysis, it is important to know to what extent surface morphology, structure and chemistry are effective and how many effective sites are present on the surface. The nitrogen atoms present in the support generate catalytically active sites; such a site of nitrogen on carbon nanotubes appears to be advantageous in providing active sites for methanol oxidation. In the present investigation, the role of nitrogen surface functionality on the carbon nanotube supported Pt electrodes for the electro-catalytic activity for methanol oxidation was evaluated both for CNT and $\mathrm{N}-\mathrm{CNT}$ and the observed activities are compared with that of the conventional electrodes.

In this work, Pt catalyst supported on nitrogen containing carbon nanotubes electrode was studied. By using nitrogen containing carbon nanotubes as support, CNT acts as threedimensional electrode, which may remain open and favour material diffusion during the electro-catalytic reaction.

\section{Experimental}

\subsection{Synthesis of CNTs from poly(paraphenylene)}

Carbon nanotubes have been synthesized by carbonizing the poly(paraphenylene) polymer inside the alumina template.
Poly(paraphenylene) was prepared on the alumina membrane template according to the method of Kovacic and Oziomek [27]. In this method, alumina membrane template was immersed in a benzene monomer solution. The monomer undergoes cationic polymerization with $\mathrm{AlCl}_{3}$ and $\mathrm{CuCl}_{2}$. The polymerization temperature was kept at $45^{\circ} \mathrm{C}$. The stirring speed was maintained around 400-500 rpm for $2 \mathrm{~h}$. Nitrogen was purged throughout the experiment. During this process, the polymer was formed from the monomers and is deposited within the pores of the alumina template. After polymerization, the alumina template was washed using water and ethyl alcohol to remove $\mathrm{CuCl}_{2}$ and aqueous acid. This synthesis method based on template yielded the tubules of the desired polymer within the pores of the alumina membrane by controlling the polymerization time and temperature. After polymerization on the membrane, the membrane was washed with deionised water and then dried. Subsequently, the membrane was carbonized in an electric furnace at $1173 \mathrm{~K}$ under argon atmosphere. The resulting carbon-alumina composite was immersed in $48 \% \mathrm{HF}$ at room temperature for $24 \mathrm{~h}$ to remove the alumina template. This is then washed with hot water to remove the residual HF.

\subsection{Synthesis of N-CNTs from poly(vinylpyrolidone)}

Polyvinylpyrrolidone (PVP, $5 \mathrm{~g}$ ) was dissolved in dichloromethane $(20 \mathrm{ml})$ and impregnated directly into the pores of the alumina template by wetting method. After complete solvent evaporation, the membrane was placed in a quartz tube $(30 \mathrm{~cm}$ length, $3.0 \mathrm{~cm}$ diameter) kept in a tubular furnace and carbonized at $1173 \mathrm{~K}$ under $\mathrm{Ar}$ gas flow. After $3 \mathrm{~h}$ of carbonization, the quartz tube was naturally cooled to room temperature. This was followed by the same procedure as described above to remove the alumina template. The nanotube was then washed with distilled water to remove the residual HF and was dried at $393 \mathrm{~K}$.

\subsection{Synthesis of N-CNTs from poly(pyrrole)}

Pyrolysis of nitrogen containing polymers is a relatively easy method for the preparation of carbon nanotube materials containing nitrogen substitution in the carbon framework. Nitrogen containing carbon nanotubes were synthesized as follows: the pyrrole monomer has been polymerized on the surface and the pore walls of the alumina template by suspending alumina template membrane in an aqueous pyrrole $(0.1 \mathrm{M})$ solution containing $0.2 \mathrm{M}$ ferric chloride hexahydrate, then to this $0.2 \mathrm{M} p$-toluene sulphonic acid was added slowly and the polymerization was carried out for $3 \mathrm{~h}$. This leads to the black coating of polypyrrole on the template membrane. The surface layers are removed by polishing with fine alumina powder and this is ultrasonicated for $5 \mathrm{~min}$ to remove the residual alumina, which was used for polishing. Then the membrane was placed inside a quartz tube $(30 \mathrm{~cm}$ length, $3.0 \mathrm{~cm}$ diameter) kept in a tubular furnace and carbonized at $1173 \mathrm{~K}$ under Ar gas flow. After $3 \mathrm{~h}$ of carbonization, the quartz tube was cooled to room temperature. This was followed by the same procedure as described above to remove the alumina template. 


\subsection{Synthesis of $N$-CNTs from poly(N-vinylimidazole)}

Poly( $N$-vinylimidazole) was synthesized on the alumina template by polymerization of $N$-vinylimidazole in benzene with AIBN as initiator. Thus, $N$-vinylimidazole $(50 \mathrm{ml})$ and AIBN $(0.5 \mathrm{~g})$ were dissolved in $250 \mathrm{ml}$ benzene and polymerized at $333 \mathrm{~K}$ under nitrogen atmosphere for $48 \mathrm{~h}$. This was followed by the same procedure as described above to remove the alumina template.

\subsection{Loading of Pt catalyst on the carbon nanotubes and nitrogen containing carbon nanotubes}

Platinum nanoclusters were loaded inside both the CNT and the N-CNT as follows; the C/alumina composite obtained (before the dissolution of template membrane) was immersed in $73 \mathrm{mM} \mathrm{H}_{2} \mathrm{PtCl}_{6}$ (aq) for $12 \mathrm{~h}$. After immersion, the membrane was dried in air and the ions were reduced to the corresponding metal by $3 \mathrm{~h}$ of exposure to flowing $\mathrm{H}_{2}$ gas at $823 \mathrm{~K}$. The underlying alumina was then dissolved by immersing the composite in $48 \% \mathrm{HF}$ for $24 \mathrm{~h}$. The membrane was then
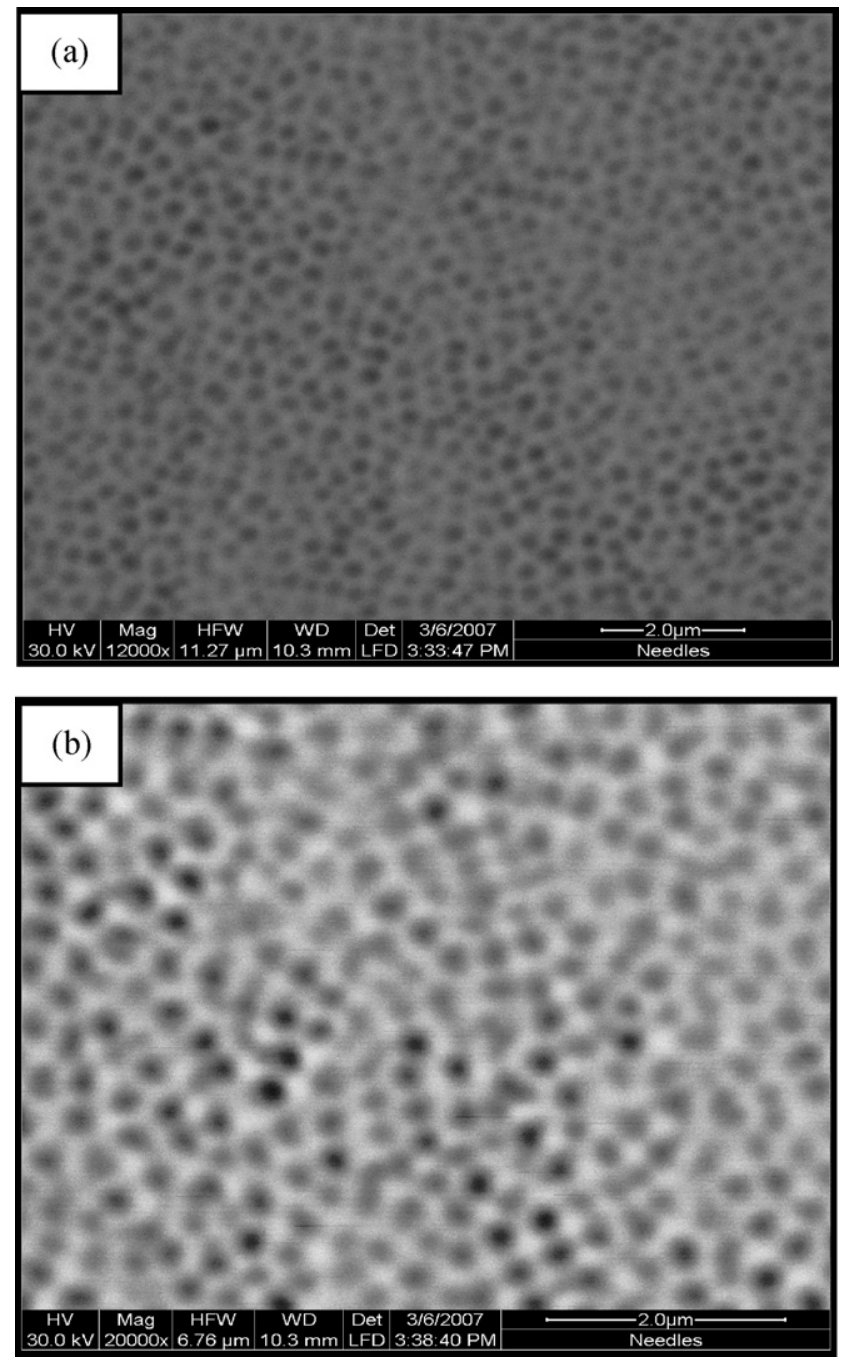

Fig. 1. SEM image of AAO template; (a) low magnification and (b) high magnification. removed from the HF solution and treated in the same way as for the unloaded CNT to remove the residual HF. This procedure resulted in the formation of $\mathrm{Pt}$ nanocluster loaded CNT and N-CNT. The complete removal of fluorine and aluminum is confirmed by EDX analysis.

\subsection{Preparation of working electrode}

Glassy carbon (BAS Electrode, $0.07 \mathrm{~cm}^{2}$ ) was polished to a mirror finish with $0.05 \mu \mathrm{m}$ alumina suspension before each experiment and served as an underlying substrate of the working electrode. In order to prepare the composite electrode, the nanotubes were dispersed ultrasonically in water at a concentration of $1 \mathrm{mg} / \mathrm{ml}$ and $20 \mu \mathrm{l}$ of the aliquot was transferred on to a polished glassy carbon substrate. After the evaporation of water, the resulting thin catalyst film was then covered with $5 \mathrm{wt} \%$ Nafion solution. And the electrode was dried at $353 \mathrm{~K}$ and is used as the working electrode.

\section{Results and discussion}

\subsection{Electron microscopy study}

\subsubsection{Scanning electron microscopy study}

The surface cross sectional view of alumina membaranes (pore diameter $200 \mathrm{~nm}$ ) is shown in Fig. 1(a and b). Fig. 1(b) shows the uniform pore present in the membrane. The pores and channels of the membrane have been effectively utilized for the polymerization and subsequent carbonization for the formation of the carbon nanotubes. AFM image show the surface morphology of AAO membranes to consist of periodically arranged pores shown in Fig. 2.

The scanning electron micrographs (SEM) of the carbon material are shown in Fig. 3(a). The Vulcan XC-72 carbon support well known as carbon black is shown in Fig. 3(a). The

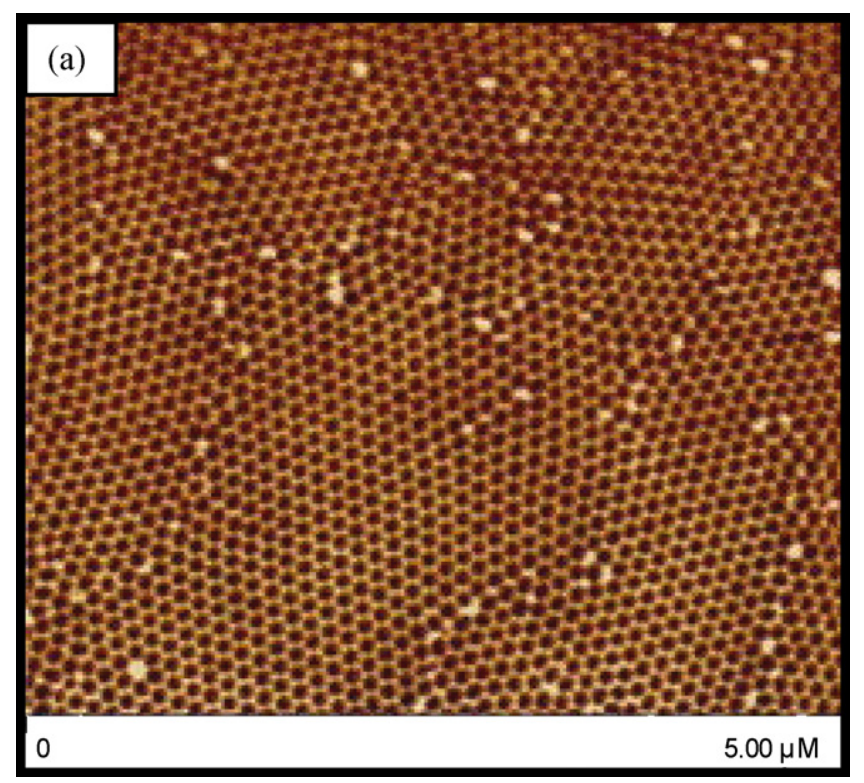

Fig. 2. AFM image of AAO template. 

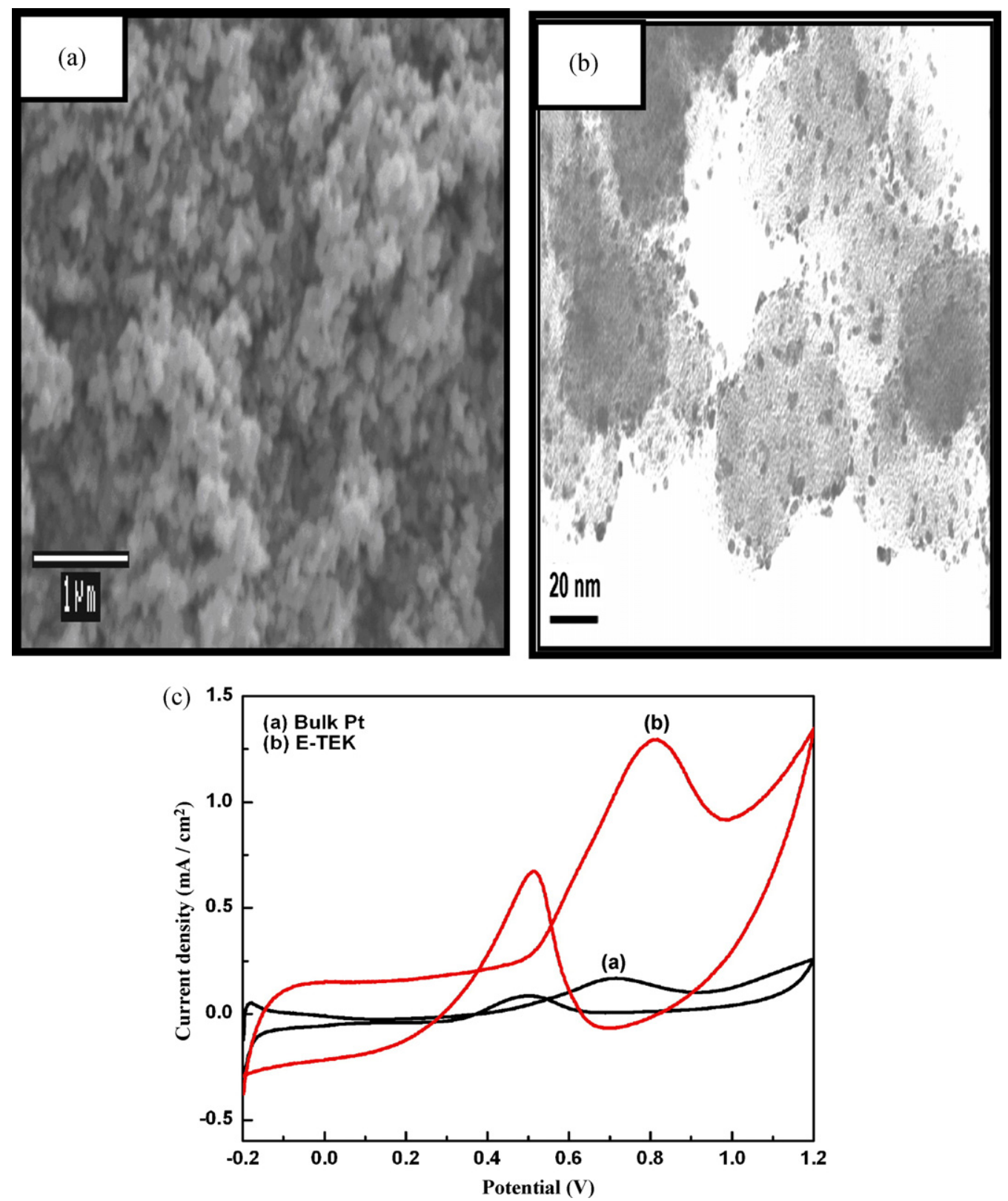

Fig. 3. (a) SEM Image of Vulcan carbon support, (b) TEM image of Pt supported Vulcan carbon support and (c) cyclic voltammetry of the Pt supported Vulcan carbon catalyst in $1 \mathrm{M} \mathrm{H}_{2} \mathrm{SO}_{4} / 1 \mathrm{M} \mathrm{CH}_{3} \mathrm{OH}$ run at $50 \mathrm{mV} / \mathrm{s}$.

agglomerated globular morphology and rough surface of the carbon particles can be observed.

The top view of the vertically aligned CNTs from poly(paraphenylene) is shown in Fig. 4(a). Fig. 5(a-c) SEM images of N-CNTs from poly(vinyl pyrolidone) shows the hollow open structure and well alignment verified by SEM. Fig. 7(b) shows the Pt deposited carbon nanotubes. SEM images of well-aligned N-CNTs prepared from poly(pyrrole), poly $(N$ vinylimidazole) is shown in Fig. 7(a) and Fig. 8(a and b).

\subsubsection{Atomic force microscopy (AFM) study}

The AFM images of the synthesized N-CNTs from poly(vinyl pyrolidone) deposited on a silicon substrate are shown in Fig. 5(d). The AFM tip was carefully scanned across the tube surface in a direction perpendicular to the tube axis.
From the AFM images, a part of the long nanotube appears to be cylindrical in shape and is found to be terminated by a symmetric hemispherical cap. Because of the finite size of the AFM tip, convolution between the blunt AFM tip and the tube body will give rise to an apparently greater lateral dimension than the actual diameter of the tube [28].

\subsubsection{Transmission electron microscopy (TEM) study}

The TEM images of Vulcan carbon support are as shown in Fig. 3(b). The TEM image of the carbon nanotubes from poly(paraphenylene) is shown in Fig. 4(b). The open end of the tube was observed by TEM, which showed that the nanotubes were hollow and the outer diameter of the nanotube closely matches with the pore diameter of the template used i.e., with a diameter of $200 \mathrm{~nm}$ and a length of approximately $40-50 \mu \mathrm{m}$. 

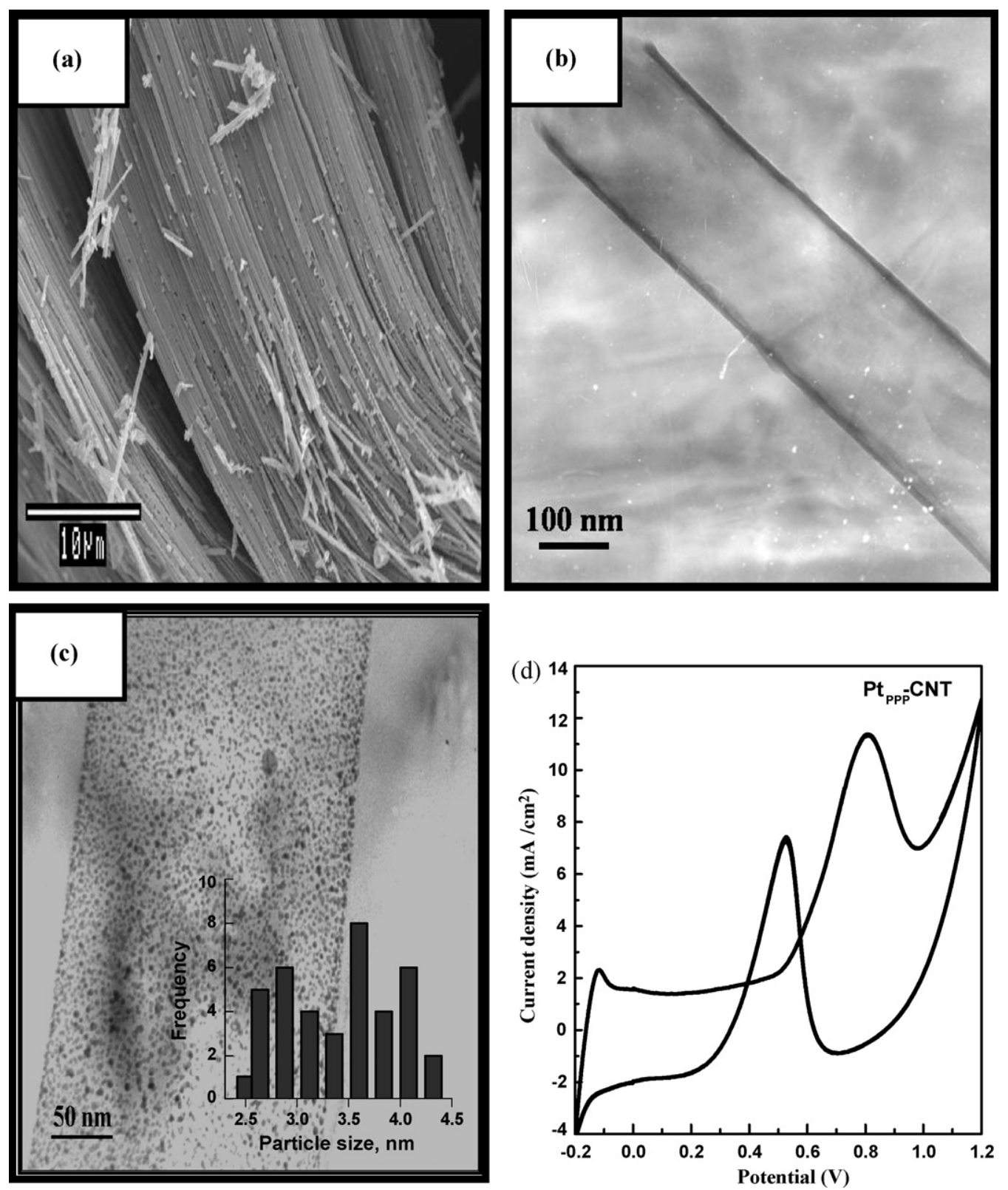

Fig. 4. (a) SEM image of carbon nanotube support from poly(paraphenylene), (b) TEM image of carbon nanotube support, (c) TEM image of Pt supported carbon nanotube support (insert figure is a histogram of Pt particle size distribution at $50 \mathrm{~nm}^{2}$ area) and (d) cyclic voltammograms of GC/CNT $\mathrm{PPP}^{-}-\mathrm{Pt}-\mathrm{Nafion}_{\text {in }} 1 \mathrm{M} \mathrm{H}_{2} \mathrm{SO}_{4} / 1 \mathrm{M}$ $\mathrm{CH}_{3} \mathrm{OH}$ run at $50 \mathrm{mV} / \mathrm{s}$.

Since no catalyst has been used for synthesis of nitrogen containing carbon nanotubes, it is worth pointing out that the nanotubes produced by template synthesis under normal experimental conditions are almost free from impurities.

The platinum catalyst has been supported on the nanotubes via impregnation. The TEM image of $\mathrm{Pt}$ nanoparticles deposited on $\mathrm{CNT}_{\mathrm{PPP}}$ obtained from poly(paraphenylene) is shown in Fig. 4(c) and the Pt particle size is $3.6 \pm 0.8 \mathrm{~nm}$. TEM images of $\mathrm{N}^{-C_{N} T_{P V P}}$ obtained from poly(vinyl pyrolidone) are shown in Fig. 6(a and b). It is evident from the images that there is no amorphous material present in the nanotube. Fig. 6(c) shows the TEM image of Pt nanoparticles filled $\mathrm{N}_{-} \mathrm{CNT}_{\mathrm{PVP}}$ obtained from poly(vinyl pyrolidone). TEM pictures reveal that the Pt particles have been homogeneously dispersed on the $\mathrm{N}_{-} \mathrm{CNT}_{\mathrm{PVP}}$ and particle sizes were found to be around $3.2 \pm 0.6 \mathrm{~nm}$. Fig. 7(c) shows the TEM image of Pt nanoparticles filled $\mathrm{N}-\mathrm{CNT}_{\mathrm{PPY}}$ obtained from poly(pyrrole) and the Pt particle size is $2.1 \pm 0.2 \mathrm{~nm}$. It can be seen from the images that there is no aggregation of $\mathrm{Pt}$ nanoparticles on the surface of the N-CNT, indicating that the surface functionalisation of the support also affects the dispersion of the Pt particles. The N-CNT anchors $\mathrm{Pt}$ particles effectively, leading to the high dispersion of Pt particles on their surface. The TEM pictures clearly revealed that the Pt particles have been homogeneously well dispersed on the nanotubes. Since the incorporation of nitrogen in CNT promotes the dispersion of nanoparticles on the surface. Further increase in the nitrogen content on the carbon 

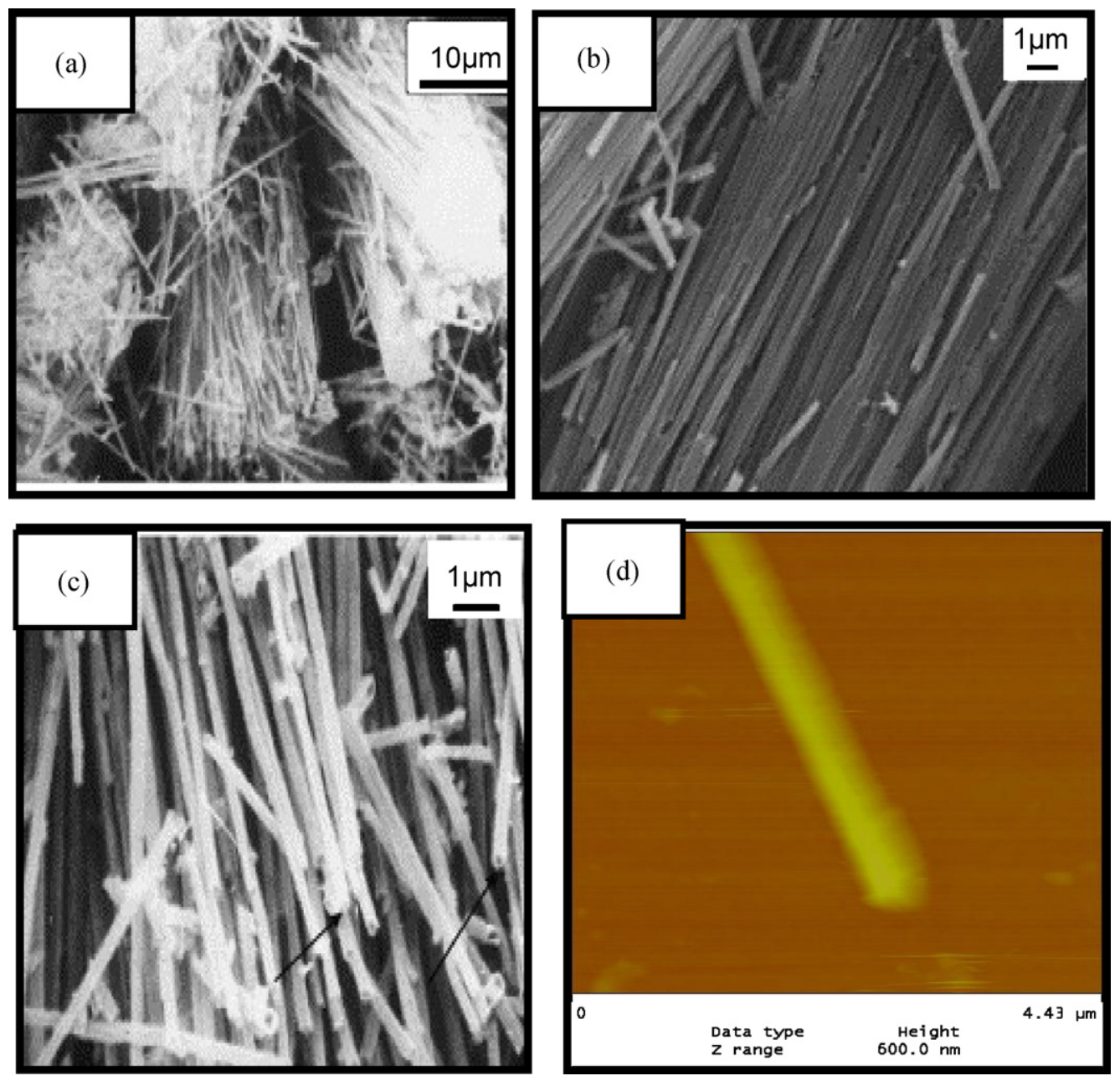

Fig. 5. (a-c) SEM images of N-CNTs from poly(vinyl pyrolidone) and (d) AFM image of the N-CNT on silicon substrate.

nanotube surface, the Pt particle tends to agglomerate as shown in Fig. 8(c) and their particle size tend to increase and average particle size was found to be around $3 \pm 0.4 \mathrm{~nm}$. The particle size of Pt for the CNT supported electrode shows particle size of around $3.6 \pm 0.8 \mathrm{~nm}$ while the N-CNT supported electrode with nitrogen content $10.5 \%$ shows particle size of around $2.1 \pm 0.2 \mathrm{~nm}$.

\subsection{Electro-catalytic activity of the catalyst}

Platinum is the best electro-catalyst for methanol oxidation reaction in direct methanol fuel cells (DMFC). The dispersion of platinum nanoparticles on the support greatly affects the activity of the catalyst. Hence, the modification of the support surface to create surface functional groups compatible to $\mathrm{Pt}$ becomes the only choice. The electro-catalytic activity of methanol oxidation of the $\mathrm{Pt} / \mathrm{N}-\mathrm{CNT}$ electrodes with variation in nitrogen content has been evaluated, which is then compared with that of the Pt/CNT electrode and the conventional carbon supported platinum (E-TEK, Pt/C $20 \mathrm{wt} \%$ ) electrode. The cyclic voltammograms of bulk $\mathrm{Pt}$ and commercial E-TEK catalysts in $1 \mathrm{M} \mathrm{H}_{2} \mathrm{SO}_{4} / 1 \mathrm{M} \mathrm{CH}_{3} \mathrm{OH}$ run at a scan rate of
$50 \mathrm{mV} / \mathrm{s}$ are shown in Fig. 3(c). The cyclic voltammograms of methanol oxidation activities of Pt supported on the CNT and $\mathrm{N}-\mathrm{CNT}$ electrodes with variation in nitrogen content was evaluated.

It is evident that the oxidation current observed with the $\mathrm{Pt}$ supported $\mathrm{N}-\mathrm{CNT}_{\mathrm{PPY}}$ electrode with $10.5 \%$ nitrogen content is showing more than sixteen fold increase in the current compared to $20 \mathrm{wt} \% \mathrm{Pt} / \mathrm{C}$ (E-TEK) electrode. The $\mathrm{Pt} / \mathrm{N}$ $\mathrm{CNT}_{\mathrm{PPY}}$ electrode with $10.5 \%$ nitrogen content is showing higher electro-catalytic activity for methanol oxidation than the other N-CNT, CNT electrode and commercial 20-wt\% Pt/C (ETEK) electrode. Pure bulk Pt electrode is showing an activity of $0.167 \mathrm{~mA} / \mathrm{cm}^{2}$. The Pt/N-CNTs showed a higher activity of $11.3 \mathrm{~mA} / \mathrm{cm}^{2}$ compared to that of Pt/CNT, which shows an activity of $7.9 \mathrm{~mA} / \mathrm{cm}^{2}$. Whereas the conventional $20-\mathrm{wt} \% \mathrm{Pt} / \mathrm{C}$ (E-TEK) electrode shows a lesser activity of $1.3 \mathrm{~mA} / \mathrm{cm}^{2}$ compared to the carbon nanotube supported electrode. These differences, which are related to both the functional groups of the support and the particle size, lead to structures that will ultimately serve to influence the catalytic activity. Possible reason for the higher electro-catalytic activity of the N-CNT electrode could be due to: (a) proper surface nitrogen functional 

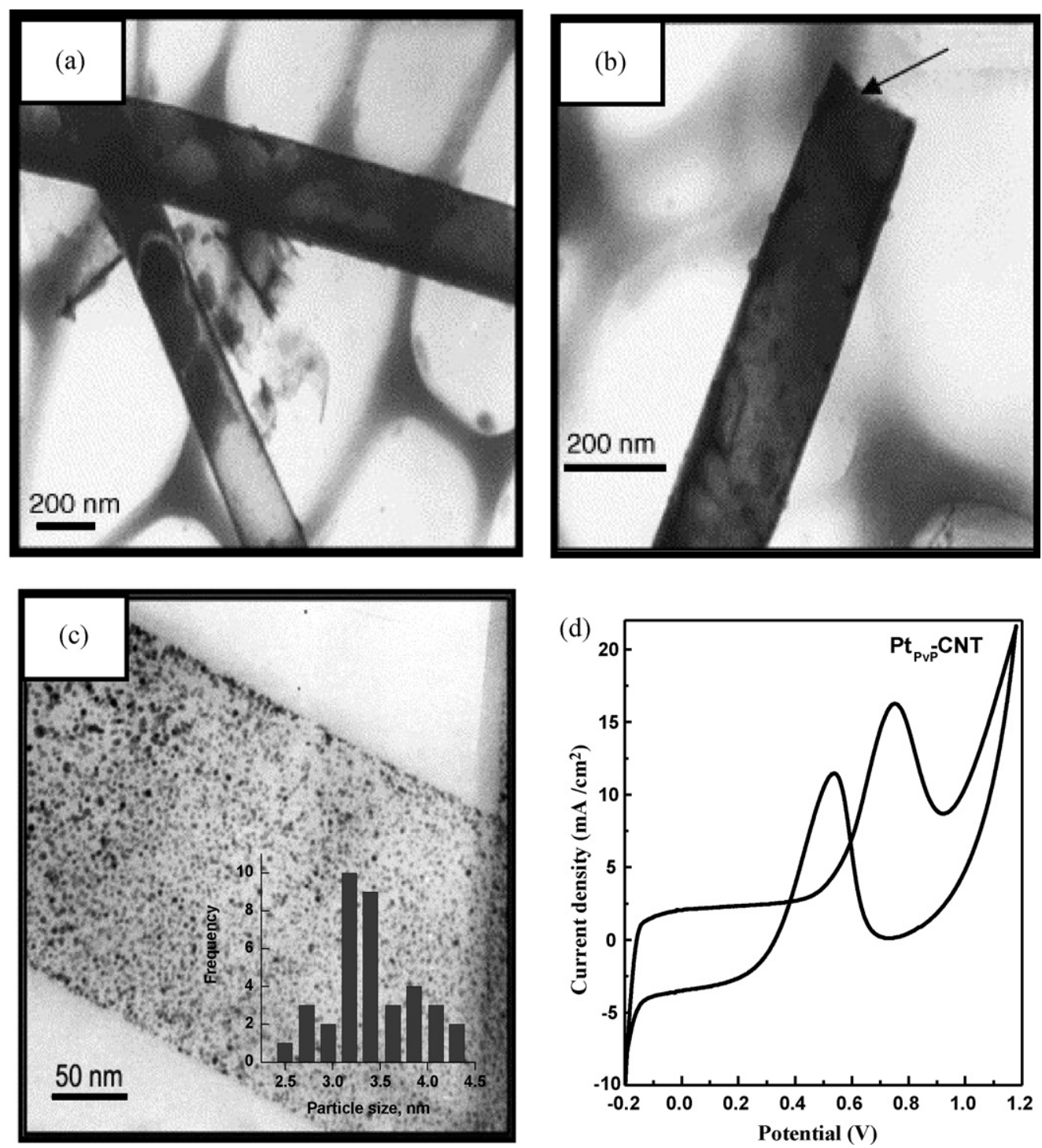

Fig. 6. (a and b) TEM images of N-CNTs from poly(vinyl pyrolidone), (c) TEM images of Pt deposited N-CNTs (insert figure is a histogram of Pt particle size distribution at $50 \mathrm{~nm}^{2}$ area) and (d) cyclic voltammogram of GC/CNT $\mathrm{PVP}_{-\mathrm{Pt}}-\mathrm{Nafion}$ in $1 \mathrm{M} \mathrm{H}_{2} \mathrm{SO}_{4} / 1 \mathrm{M} \mathrm{CH}_{3} \mathrm{OH}$ run at $50 \mathrm{mV} / \mathrm{s}$.

groups on the support, (b) moderate nitrogen surface functional groups enhance the Pt-CNT interaction and (c) optimum nitrogen content on the support increases high platinum uniform dispersion on the support.

The Vulcan carbon support has randomly distributed pores of varying sizes which may make fuel and product diffusion difficult whereas the tubular three-dimensional morphology of the nitrogen containing carbon nanotube makes the fuel diffusion easier. The Vulcan carbon contains high levels of sulphur (ca. $5000 \mathrm{ppm}$ or greater), which could potentially poison the fuel cell electro-catalysts (Swider and Rolison [20]). The Pt particles can be anchored to the surface of the carbon nanotubes by nitrogen functional groups. The Pt particles coordinating with the nitrogen on the surface determines the strength of the metal-support interaction. The observed effect of metal-support interaction between N-CNT and platinum may have a control in the growth of a particular crystalline plane of Pt. Consequently, the metal-support interaction greatly influences the methanol oxidation activity. According to the model of van Dam and van Bekkum the ionization behaviour of the carbon surface based on independent acid and basic groups, leads to the conclusion that the acidic oxygen surface groups should be considered as weak anchoring sites (Swider and Rolison [19]). On this basis, the carbon surface basic sites of nitrogen act as anchoring sites for the hexachloroplatinic anion and are responsible for the strong adsorption of platinum on the carbon nanotube surface. The nature of the carbon surface basic sites is still a subject of discussion. The carbon surface basic sites are frequently associated with pyrone like structure. In NCNT, the surface active sites are essentially of Lewis type and are associated with the $\pi$-electron rich regions within the basal planes. The nitrogen functionality on the carbon surface develops basic sites with moderate strength and shows strong interaction with $\mathrm{H}_{2} \mathrm{PtCl}_{6}$ during impregnation, which would favour the Pt dispersion on the carbon surface. The high $\mathrm{Pt}$ dispersion on the nitrogen containing carbon nanotubes support 

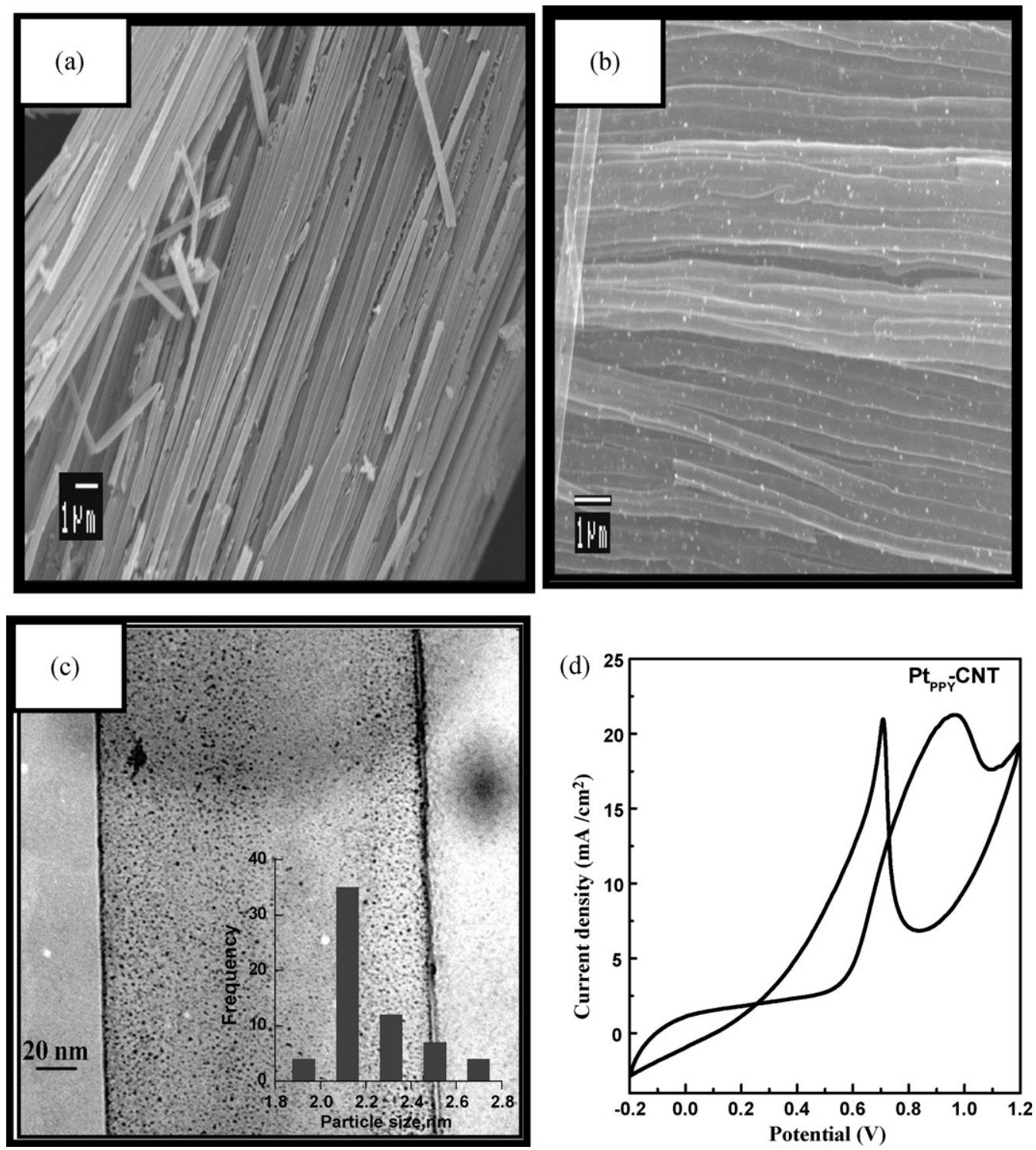

Fig. 7. (a) Scanning electron micrographs of N-CNTs support from poly(pyrrole), (b) SEM images of Pt deposited N-CNTs, (c) TEM images of Pt deposited N-CNTs (insert figure is a histogram of Pt particle size distribution at $50 \mathrm{~nm}^{2}$ area) and (d) cyclic voltammograms of GC/CNT $\mathrm{PPY}_{-}-\mathrm{Pt}_{-} \mathrm{Nafion}$ in $1 \mathrm{M} \mathrm{H}_{2} \mathrm{SO}_{4} / 1 \mathrm{M} \mathrm{CH}_{3} \mathrm{OH}$ run at $50 \mathrm{mV} / \mathrm{s}$.

is attributed to the surface properties of the carbon nanotubes, resulting in strong $\mathrm{Pt} / \mathrm{N}-\mathrm{CNT}$ interaction.

The N-CNT electrodes show higher catalytic activity compared to CNT electrodes, which shows the catalytic effect of nitrogen functionalisation on the carbon nanotubes. Finally, the dispersed platinum electrodes obtained by stabilization of colloidal metallic particles on N-CNT support with nitrogen content $10.5 \%$ display a high activity for the oxidation of methanol. Therefore, it is likely that the influence of the composition of the support and in particular the nitrogen functionalisation of the carbon nanotube support directly influences the catalytic properties of the Pt particles. In addition, particle aggregation is not observed, which indicates that the surface morphology also affects the dispersion of the Pt particles. The nitrogen containing carbon nanotubes lead to higher dispersion of Pt particles on its surface, which is attributed to the surface properties of the nitrogen containing carbon nanotube and this result in a strong Pt/N-CNT interaction. On the contrary, lack of active sites on CNT results in fewer but larger Pt particles on the surface of CNT.

In order to see the effect of the nitrogen content in the carbon nanotube, the catalytic activity was evaluated by increasing the percentage of nitrogen in the carbon nanotube from 0 to $16.7 \%$. The variation of nitrogen content has been done by fixing the polymer source. It is evident from Table 1 . The catalytic activity for methanol oxidation increases as nitrogen content increases. There is a decrease in the activity when nitrogen content is increased above $10.5 \%$. The nitrogen containing carbon nanotubes prepared from polypyrrole precursor shows high catalytic activity and stability towards methanol oxidation. 

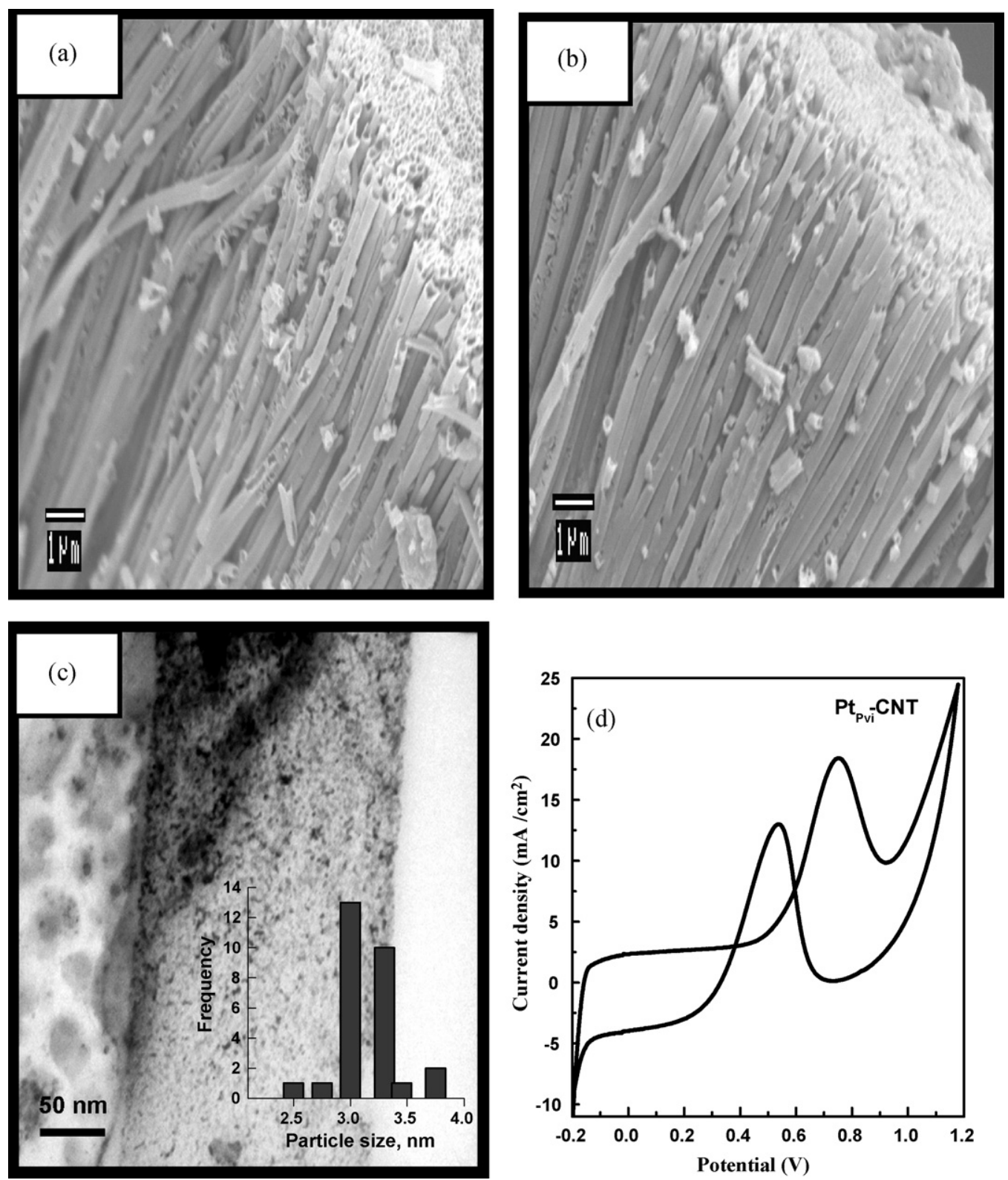

Fig. 8. (a and b) Scanning electron micrographs of N-CNTs support from poly(vinyl imidazole), (c) TEM images of Pt deposited N-CNTs (insert figure is a histogram of Pt particle size distribution at $50 \mathrm{~nm}^{2}$ area) and (d) cyclic voltammograms of GC/CNT $\mathrm{PVI}-\mathrm{Pt}-\mathrm{Nafion}$ in $1 \mathrm{M} \mathrm{H}_{2} \mathrm{SO}_{4} / 1 \mathrm{M} \mathrm{CH}_{3} \mathrm{OH}$ run at $50 \mathrm{mV} / \mathrm{s}$.

\subsection{Chronoamperometry of the catalyst}

Chronoamperometry was used to characterize the stability of the electrodes. Long-term stability is very important for practical applications. The current density-time plots of

Table 1

Electro-catalytic activity of methanol oxidation on various electrodes

\begin{tabular}{lll}
\hline Electro-catalyst & $\begin{array}{l}\text { Nitrogen } \\
\text { content }(\%)\end{array}$ & $\begin{array}{l}\text { Activity Ip } \\
\left(\mathrm{mA} / \mathrm{cm}^{2}\right)\end{array}$ \\
\hline $\mathrm{Pt}$ & - & 0.076 \\
GC/E-TEK 20\% Pt/C-Nafion & - & 1.3 \\
GC/CNT $_{\mathrm{PPP}}-\mathrm{Pt}-\mathrm{Nafion}$ & 0.0 & 12.4 \\
GC/CNT $_{\mathrm{PVP}}-\mathrm{Pt}-\mathrm{Nafion}$ & 6.63 & 16.2 \\
GC/CNT $_{\mathrm{PPY}}-\mathrm{Pt}-\mathrm{Nafion}$ & 10.5 & 21.4 \\
GC/CNT $_{\mathrm{PVI}}-\mathrm{Pt}-\mathrm{Nafion}$ & 16.7 & 18.6 \\
\hline
\end{tabular}

various electrodes in $1 \mathrm{M} \mathrm{H}_{2} \mathrm{SO}_{4}$ and $1 \mathrm{M} \mathrm{CH}_{3} \mathrm{OH}$ at $0.6 \mathrm{~V}$ are shown in Fig. 9. The performance of Pt electrodes was found to be poor compared to that of the E-TEK, Pt/CNT and $\mathrm{Pt} / \mathrm{N}-\mathrm{CNT}$ electrodes. The N-CNT supported electrodes are found to be the most stable for direct methanol oxidation. The increasing order of stability of various electrodes is: $\mathrm{Pt}$ $<\mathrm{Pt} /$ Vulcan $(\mathrm{E}-\mathrm{TEK})<\mathrm{Pt} / \mathrm{CNT}_{\mathrm{ppp}}<\mathrm{Pt} / \mathrm{N}-\mathrm{CNT}_{\mathrm{pvp}}<\mathrm{Pt} / \mathrm{N}-$ $\mathrm{CNT}_{\mathrm{Pvi}}<\mathrm{Pt} / \mathrm{N}-\mathrm{CNT}_{\mathrm{Ppy}}$. It must be noted that the current density (specific activity) and stability is the highest for the $\mathrm{Pt} /$ $\mathrm{N}-\mathrm{CNT}_{\text {ppy }}$ electrodes. It is also found that the metal particle distribution on the N-CNT support and metal-support interactions are important parameters contributing to the activity of the catalyst. Thus, the higher activity of the Pt/N-CNT $\mathrm{PPY}_{\text {electrode }}$ with $10.5 \%$ nitrogen content may be attributed to the small particle size, higher dispersion of platinum and the nature of CNTs supports (metal-support interaction). 


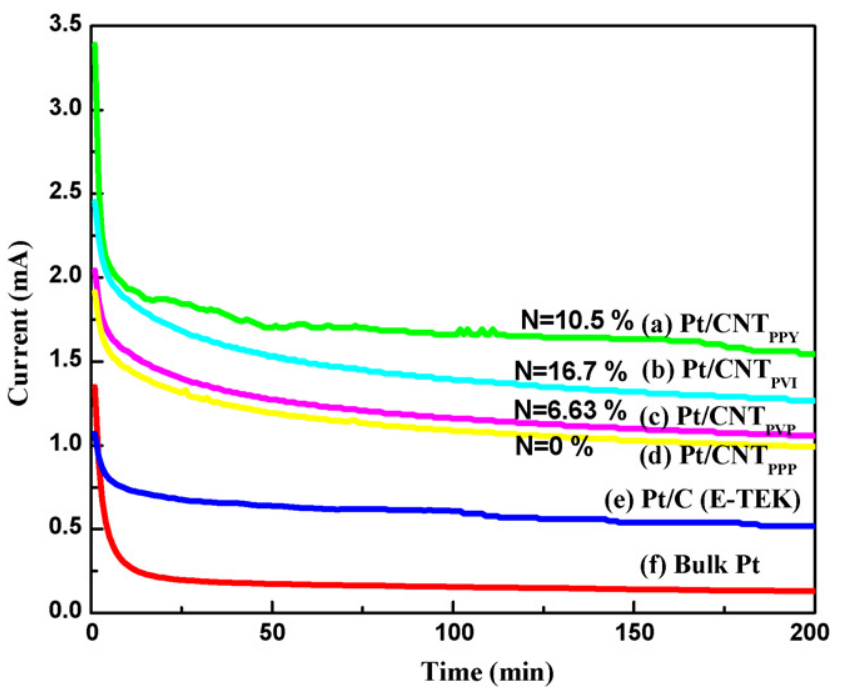

Fig. 9. Chronoamperogram curves for (a) $\mathrm{Pt} / \mathrm{N}-\mathrm{CNT}_{\mathrm{PPY}}$, (b) $\mathrm{Pt} / \mathrm{N}-\mathrm{CNT}_{\mathrm{PVI}}$, (c) $\mathrm{Pt} / \mathrm{N}_{-} \mathrm{CNT}_{\mathrm{PVP}}$ (d) $\mathrm{Pt} / \mathrm{CNT}_{\mathrm{PPB}}$, (e) carbon supported platinum, (f) 20 -wt $\% \mathrm{Pt} / \mathrm{C}$ (E-TEK) and (g) Pt measured in $1 \mathrm{M} \mathrm{H}_{2} \mathrm{SO}_{4}+1 \mathrm{M} \mathrm{CH}_{3} \mathrm{OH}$. The potential was stepped from the rest potential to $0.6 \mathrm{~V}$ vs. $\mathrm{Ag} / \mathrm{AgCl}$.

\section{Conclusion}

In summary, the dispersion and electro-catalytic activity of methanol oxidation for platinum nanoparticle on nitrogen containing carbon nanotubes with variation in nitrogen content have been investigated. The amount of nitrogen in the CNT plays an important role as observed by the increase in activity and stability of methanol oxidation with Nitrogen content, probably due to the hydrophilic nature of the CNT. It is found that the Pt particles supported on N-CNT with $10.5 \%$ nitrogen content show excellent electro-catalytic activity for methanol oxidation than the CNT and the commercial carbon supported platinum (E-TEK) electrodes. Higher activity of Pt nanoparticles supported N-CNT has been discussed based on the metal-support interaction. The use of N-CNT as supports for Pt electrodes shows higher electrocatalytic activity, involving high platinum dispersion, strong metal-support interaction and high stability, which are important practical considerations in fuel cell technology.

\section{References}

[1] M. Uchida, Y. Aoyama, N. Tanabe, N. Yanagihara, N. Eda, A. Ohta, J. Electrochem. Soc. 142 (1995) 2572-2576.
[2] E. Antolini, Appl. Catal. B 74 (2007) 324-336.

[3] E. Antolini, Appl. Catal. B 74 (2007) 337-350.

[4] C.A. Bessel, K. Laubernds, N.M. Rodriguez, R.T.K. Baker, J. Phys. Chem. B 105 (2001) 1115-1118.

[5] E.S. Steigerwalt, G.A. Deluga, C.M. Lukehart, J. Phys. Chem. B 106 (2002) 760-766.

[6] W.Z. Li, C.H. Liang, W.J. Zhou, Q. Xin, J. Phys. Chem. B 107 (26) (2003) 6292-6299.

[7] V. Selvaraj, M. Alagar, K. Sathish Kumar, Appl. Catal. B 75 (2007) 129138.

[8] C. Kim, Y.J. Kim, Y.A. Kim, T. Yanagisawam, K.C. Park, M. Endo, M.S. Dresselhaus, J. Appl. Phys. 96 (2004) 5903-5905.

[9] C. Wang, M. Waje, X. Wang, J.M. Tang, R.C. Haddon, Y.S. Yan, Nano Lett. 4 (2004) 345-348.

[10] T. Yoshitake, Y. Shimakawa, S. Kuroshima, H. Kimura, T. Ichihashi, Y. Kubo, Physica B 323 (2002) 124-126.

[11] T. Hyeon, S. Han, Y.E. Sung, K.W. Park, Y.W. Kim, Angew. Chem. Int. 42 (2003) 4352-4356

[12] O. Stephan, P.M. Ajayan, C. Colliex, P.H. Redlich, J.M. Lambert, P. Bernier, Science 266 (1994) 1683-1685.

[13] M. Glerup, M. Castignolles, M. Holzinger, G. Hug, A. Loiseau, P. Bernier, Chem. Commun. (2003) 2542-2543.

[14] M. Terrones, P.M. Ajayan, F. Banhart, X. Blase, D.L. Carroll, J.C. Charlier, Appl. Phys. A Mater. 74 (2002) 355-361.

[15] R. Czerw, M. Terrones, J.-C. Charlier, X. Blase, B. Foley, R. Kamalakaran, Nano Lett. 1 (9) (2001) 457-460.

[16] K. Jurewicz, K. Babeł, A. Ziółkowski, H. Wachowska, Electrochim. Acta 48 (2003) 1491-1498.

[17] A. Zeng, E. Liu, S.N. Tan, S. Zhang, J. Gao, Electroanalysis 14 (15-16) (2002) 1110-1115.

[18] S.C. Roy, P.A. Christensen, A. Hamnett, K.M. Thomas, V. Trap, J. Electrochem. Soc. 143 (10) (1996) 3073-3079.

[19] K.E. Swider, D.R. Rolison, Electrochem. Solid State Lett. 3 (1) (2000) 4 6.

[20] K.E. Swider, D.R. Rolison, J. Electrochem. Soc. 143 (3) (1996) $813-$ 819.

[21] M.R. Tarasevich, V.A. Bogdanovskaya, Russ. Chem. Rev. 56 (7) (1987) 653-669.

[22] M.R. Tarasevich, L.A. Beketaeva, B.N. Efremov, N.M. Zagudaeva, L.N. Kuznetsova, K.V. Rybalka, Russ. J. Electrochem. 40 (5) (2004) $542-551$.

[23] A.K. Shukla, M.K. Ravikumar, A. Roy, S.R. Barman, D.D. Sarma, A.S. Arico, J. Electrochem. Soc. 141 (6) (1994) 1517-1522.

[24] S.C. Roy, A.W. Harding, A.E. Russell, K.M. Thomas, J. Electrochem. Soc. 144 (7) (1997) 2323-2328.

[25] S. Maldonado, K.J. Stevenson, J. Phys. Chem. B 109 (2005) 47074716.

[26] C.-L. Sun, L.-C. Chen, M.C. Su, L.-S. Hong, O. Chyan, C.-Y. Chan, Chem. Mater. 17 (14) (2005) 3749-3753.

[27] P. Kovacic, J. Oziomek, J. Org. Chem. 29 (1964) 100-104.

[28] S.C. Tsang, P. de Oliveira, J.J. Davis, M.L.H. Green, H.A.O. Hill, Chem. Phys. Lett. 249 (1996) 413-422. 